\title{
Multiple Primary Lung Cancers: A New Challenge in the Era of Precision Medicine
}

This article was published in the following Dove Press journal:

Cancer Management and Research

\author{
Lishu Zhao (D) \\ Chaoyuan Liu \\ Guiyuan Xie \\ Fang $\mathrm{Wu}$ (1) \\ Chunhong $\mathrm{Hu}$ \\ Department of Oncology, The Second \\ Xiangya Hospital, Central South \\ University, Changsha 4I00II, Hunan, \\ People's Republic of China
}

\begin{abstract}
With the widespread implementation of lung cancer screening, more and more patients are being diagnosed with multiple primary lung cancers (MPLCs). In the era of precision medicine, many controversies remain in differentiating MPLCs from intrapulmonary metastasis and the optimum treatment choice, especially in patients exhibiting similar histology. In this review, we summarize common diagnostic criteria and novel discrimination methods with a special emphasis on the emerging value of broad panel next-generation sequencing (NGS) for the diagnosis of MPLCs. We then discuss current advances regarding therapeutic approaches for MPLCs. Radical surgery is the main treatment modality, while stereotactic body radiotherapy (SBRT) is safe and feasible for early-stage MPLC patients with inoperable tumors. In addition, immunotherapy and targeted therapy, particularly epidermal growth factor receptor-tyrosine kinase inhibitors, are emerging therapeutic strategies that are still in their infancy. Characteristics of both genomic profiles and tumor microenvironment are currently being evaluated but warrant further exploration to facilitate the application of targeted systematic therapies in MPLC patients.
\end{abstract}

Keywords: multiple primary lung cancers, MPLCs, diagnosis, surgery, stereotactic body radiation therapy, SBRT, targeted therapy, immunotherapy

\section{Introduction}

Worldwide, lung cancer has the highest cancer mortality among multiple types of malignances. ${ }^{1}$ With the widespread application of computed tomography (CT) and lung cancer screening, lung cancer patients have a $20-39 \%$ reduction in the mortality rate and an improved 5-year survival rate. ${ }^{1}$ As lifespans lengthen, up to $15 \%$ of patients with lung cancer harbor a second primary lung cancer. ${ }^{2-6}$ Furthermore, it has been estimated that the incidence rate of a second primary lung cancer following initial treatment of non-small cell lung cancer (NSCLC) at 3 years, 5 years, 8 years are $5 \%, 8 \%$, and $16 \%$, respectively. ${ }^{7}$ In the case of multifocal lung cancers, discriminating multiple primary lung cancers (MPLCs) from intrapulmonary metastasis (IM) remains a common dilemma in the clinical setting. The main reason for the difficulty in identification is that the histological types are identical in most patients with multifocal lung cancers, with adenocarcinoma being the most frequent $(\sim 88 \%))^{2,8,9}$ Existing diagnostic criteria are mainly based on clinicopathological features, ${ }^{10-12}$ and are far from meeting the clinical need. Nonetheless, great efforts have been made worldwide to explore novel and more accurate methods of identifying independent primary tumors from metastasis. 
Most MPLC patients are diagnosed at the early stages of the disease; thus surgical intervention represents one of the most common therapeutic approaches, ${ }^{13}$ although it is not applicable to patients with limited pulmonary function or to those with super multiple pulmonary nodules. ${ }^{14-16}$ For these patients, novel systematic therapies including targeted therapy and immunotherapy are warranted and should be explored. With the advancement of multiple technologies, particularly next-generation sequencing (NGS), great progress has been made in diagnosing and treating MPLCs. Herein, we performed a literature search of the PubMed and Web of Science (WoS) databases as of May 31, 2020 using the keywords ("multiple primary lung cancer" OR "MPLC" OR "multiple ground-glass opacities" OR "multiple GGOs"), and retrieved the available studies associated with diagnosis and treatment of MPLCs. In this review, we summarize existing diagnostic criteria and therapies for MPLC patients and discuss novel diagnostic methods for discrimination of MPLCs and emerging therapeutic options, with the aim of helping clinicians to better recognize and manage such patients.

\section{Diagnostic Criteria and Stage Diagnostic Criteria}

MPLCs are divided into synchronous MPLCs (sMPLCs) and metachronous MPLCs (mMPLCs). Despite no globally recognized guidelines, three diagnostic criteria for sMPLCs and mMPLCs have been widely used in the clinical setting. ${ }^{10-12}$

Martini et $\mathrm{al}^{10}$ firstly established the diagnostic criterion for MPLCs in 1975 (Table 1). MPLCs are diagnosed if they present different histological types, while there are subtle differences in the diagnosis of SMPLCs and mMPLCs if tumors share the same histological type. sMPLCs originate from carcinomas in situ, occur in different segments, and have no carcinoma in the common lymphatic drainage sites and extrapulmonary sites. mMPLCs are diagnosed if tumors originate from carcinomas in situ, or are located in different lobes rather than segments, or have a free interval between cancers $\geq 2$ years. The Martini-Melamed criteria based on clinicopathological features are practical and have been put into routine clinical use, but a lack of accuracy exists in distinguishing MPLCs from IM when histological types are identical.

Subsequently, with the development of molecular biology and NGS technology, the Martini-Melamed criteria were revised and improved. The American College of Chest Physicians ${ }^{11,17,18}$ added different molecular genetic characteristics as a diagnostic criterion for both SMPLCs and mMPLCs (Table 1). When histological types are

Table I Three Common Diagnostic Criteria for Multiple Primary Lung Cancers

\begin{tabular}{|c|c|c|}
\hline Martini Melamed criteria ${ }^{10}$ & ACCP guidelines" & TNM staging system (8th edition) ${ }^{12}$ \\
\hline $\begin{array}{l}\text { sMPLCs: } \\
\text { I. Tumors physically distinct and separate } \\
\text { 2. Histology: } \\
\text { A. Different histological types } \\
\text { B. Same histological type, but in different segments, lobes, } \\
\text { if origin from carcinoma in situ } \\
\text { And no carcinoma in lymphatics common to both } \\
\text { And no extrapulmonary metastases }\end{array}$ & $\begin{array}{l}\text { sMPLCs: } \\
\text { I. Different histology } \\
\text { 2. Different molecular genetic } \\
\text { characteristics } \\
\text { 3. Arising from a separate focus of } \\
\text { carcinoma in situ } \\
\text { 4. Same histology, if: } \\
\text { Tumors in different lobes } \\
\text { And no N2, N3 involvement } \\
\text { And no systemic metastases }\end{array}$ & $\begin{array}{l}\text { Clinical Criteria for sMPLCs: } \\
\text { I. Different histological types on biopsy } \\
\text { 2. Arguments favoring sMPLCs: } \\
\text { Different radiographic appearance or } \\
\text { metabolic uptake } \\
\text { Different growth rates } \\
\text { Different biomarker pattern } \\
\text { Absence of lymphatic or systemic } \\
\text { metastases }\end{array}$ \\
\hline $\begin{array}{l}\text { mMPLCs: } \\
\text { I. Different histological types } \\
\text { 2. Same histological type, if: } \\
\text { Free interval between cancers } \geq 2 \text { years } \\
\text { Or origin from carcinoma in situ } \\
\text { Or second cancer in different lobes and no carcinoma in } \\
\text { common lymphatics and extrapulmonary sites }\end{array}$ & $\begin{array}{l}\text { mMPLCs: } \\
\text { I. Different histology } \\
\text { 2. Different molecular genetic } \\
\text { characteristics } \\
\text { 3. Arising from a separate focus of } \\
\text { carcinoma in situ } \\
\text { 4. Same histology, temporarily separated, if: } \\
\text { Free interval between cancers } \geq 4 \text { years } \\
\text { And no systemic metastases }\end{array}$ & $\begin{array}{l}\text { Pathologic criteria for sMPLCs (e. } \\
\text { g., after resection): } \\
\text { I. Different histological types } \\
\text { 2. Clearly different comprehensive } \\
\text { histologic assessment } \\
\text { 3. Squamous carcinomas arising from } \\
\text { carcinoma in situ. } \\
\text { 4. Arguments favoring sMPLCs: } \\
\text { Different biomarker pattern } \\
\text { Free of lymphatic or systemic metastases. }\end{array}$ \\
\hline
\end{tabular}

Abbreviations: ACCP, American College of Chest Physicians; sMPLCs, synchronous multiple primary lung cancers; mMPLCs, metachronous multiple primary lung cancers. 
identical, different lobes are required for diagnosing sMPLCs in terms of location of tumors and the interval between the development of mMPLCs is extended to four years or above. It has also been suggested that multiple adenocarcinomas should be distinguished based on the proportion of histologic subtypes (eg, lepidic, papillary, micropapillary, acinar), and the consultation of a multidisciplinary team should be taken into consideration in diagnosing MPLCs. However, it is difficult to determine whether a second cancer is primary tumor or a metastatic tumor with an interval of 2 to 4 years between tumors. No specific molecular biomarkers were mentioned.

According to the American Joint Committee on Cancer (AJCC) TNM staging system (8th edition), ${ }^{12}$ multiple lung cancers may be considered as clinical sMPLCs if they present different histology on biopsy and as pathological sMPLCs, if the histological types or comprehensive histologic assessment (CHA) are clearly different, or they are squamous carcinomas that arise from carcinoma in situ (Table 1). This was the first time that CHA was added as a diagnostic criterion, but some limitations of this classification should be mentioned. The diagnostic criteria for mMPLCs is beyond the scope of the cancer staging manual and the feature of a clearly different CHA is unclearly defined.

\section{Stage}

In 2007, multifocal lung cancers were regarded as IM in the 7th edition of the TNM classification, which categorized multiple same-lobe cancers as T3, ipsilateral different-lobe cancers as T4 and bilateral lung cancers as M1. ${ }^{19}$ Subsequently in 2017, the 8th edition of the TNM classification for lung cancer indicated that synchronous or metachronous independent lung cancers should each be classified with a separate TNM stage and be managed individually regardless of the location of the tumors. ${ }^{12,20,21}$

\section{Differential Diagnosis}

In clinical practice, it is difficult to differentiate MPLCs from IM solely based on the criteria described above, especially when multifocal lung cancers are of identical histological types. Below, we summarized the role of radiological, clinicopathological and molecular characteristics in distinguishing MPLCs from IM.

\section{Radiological Appearance}

CT or positron emission tomography-computed tomography (PET-CT) could aid in the differential diagnosis in the absence of tumor tissues. Multifocal GG/L lung cancers manifest as having ground-glass opacities (GGOs) on CT scans or lepidic cancers on pathology. ${ }^{12,20,22}$ Multifocal GG/L lung cancers include adenocarcinoma in situ, minimally invasive adenocarcinoma, and lepidic-predominant adenocarcinoma, and are considered as independent primary tumors. ${ }^{23-25}$ A study proposed that multifocal lung cancers with at least one GGO were radiological MPLCs due to a good prognosis. ${ }^{26}$ However, early metastasis was detected by two GGOs in the same individual based on many shared mutations, indicating the presence of spread through air spaces (STAS). ${ }^{14,27}$ The World Health Organization (WHO) first defined STAS as spread of tumor cells adjacent to the margins of the tumor into air spaces in the surrounding lung parenchyma and suggested that the morphological features of tumor STAS included micropapillary clusters, solid nests, or single tumor cell. ${ }^{28,29}$ STAS are connected to tumors by lung alveoli, and the median distance from STAS to the tumor margin is less than $1 \mathrm{~cm} .{ }^{30}$ There is evidence indicating that STAS is an unfavorable prognostic factor for patients with stage I lung cancers after sublobectomy, ${ }^{29,31-33}$ but not for patients after lobectomy. ${ }^{32}$ It suggests that STAS may not occur across lobes, so multifocal GG/L lung cancers cannot always be regarded as MPLCs but they may be if they are located on different lobes. Further studies are needed for verification, which will be of great help in classifying patients with multiple lung cancers manifesting as GGOs.

Additionally, PET-CT could discriminate MPLCs from IM based on the difference or ratio of standardized uptake values (SUVs) between tumors in each patient. ${ }^{34,35}$ A clinical trial (NCT03679936) is designed to investigate the value of dynamic PET-CT to diagnose MPLCs. However, it's not enough to distinguish MPLCs from IM relying merely on CT or PET-CT. Suh et $\mathrm{al}^{36}$ established a novel diagnostic algorithm for MPLCs by combining SUVs from PET-CT with radiological features on CT including GGOs, spicule sign, and air-bronchogram. Tumor pairs were diagnosed as MPLCs if one of the following criteria was met: any tumor presents with pure GGOs or GGO-dominant features; both tumors harbor spiculation or air-bronchogram; only one tumor harbors spiculation or air-bronchogram and tumors pairs have more than two grades of SUVs. In contrast to the 
histopathological classification, radiological classification achieves a satisfying positive predictive value and provides a convenient and noninvasive way to diagnose MPLCs. But large-scale studies are required to validate its accuracy and utility as a reliable diagnostic criterion.

Recently, artificial intelligence and machine learning approaches have been increasingly applied to biomedical studies including radiology, pathology, and oncology. ${ }^{37-39}$ Analyzing features of radiological images by machine learning algorithms could aid in the diagnosis of benign pulmonary nodules, primary, and metastatic lung cancer. $^{40,41}$ Therefore, machine learning-based image analysis may represent a novel approach for identifying independent primary tumors in patients with multiple lung lesions. In the future, integrating radiological imaging with pathological and genomic data using artificial intelligence and machine learning may promote more accurate diagnosis for MPLCs.

\section{Histopathological Characteristics}

Histopathology is the gold standard for diagnosing lung cancer, but it is difficult to identify MPLCs versus IM when multifocal lung cancers are of the same histological type, particularly adenocarcinoma. According to the 2004 WHO classification, lung adenocarcinoma was defined as morphologically heterogeneous and often had mixed subtypes (acinar, papillary, micropapillary, bronchioloalveolar, and solid). ${ }^{42}$ Subsequently, Girard et $\mathrm{al}^{43}$ developed a histopathological classification to distinguish MPLCs from IM, also known as comprehensive histologic assessment (CHA). Not only percentages of histologic subtypes in $10 \%$ increments but also cytologic and stromal characteristics were assessed in this classification. Tumors were considered MPLCs if tumor pairs had different histological types, or the predominant subtypes of adenocarcinomas were different (ie, acinar, papillary), or cytologic and stromal characteristics differed when tumor pairs were squamous cell carcinomas. Tumors were metastatic if they had similar percentages of histologic subtypes or cytologic and stromal characteristics. CHA was confirmed to be highly consistent with the molecular classification.

With the update of the WHO classification to the 2015 version, the subtyping of bronchoalveolar carcinoma was abandoned, and the lepidic component was introduced. ${ }^{44}$ Invasive adenocarcinoma was semi-quantitatively assessed in 5\% increments according to five subtypes: lepidic, acinar, papillary, micropapillary, and solid. Subsequently,
CHA was combined with a low-grade lepidic component to distinguish MPLCs from IM. ${ }^{45}$ The low-grade lepidic tumors, resembling type II pneumocytes or Clara cells, had nuclei with slightly irregular shape and size. Compared with CHA, multiple tumors possessing low-grade lepidic component were also considered as MPLCs in this modified CHA. ${ }^{45}$ Several studies demonstrated that CHA combined with a low-grade lepidic component could further improve diagnostic accuracy. ${ }^{45,46}$

In summary, CHA alone or combined with a low-grade lepidic component appears to be a less expensive and faster way to distinguish MPLCs but it also has some limitations. First, CHA requires a suitable amount of tumor tissues, so it is not available prior to surgery. Secondly, evaluating a percentage of histological subtype or the stromal characteristics is relatively subjective due to interobserver variations. Finally, CHA may conflict with the molecular classification and currently it is unknown which classification is superior.

\section{Molecular Characteristics}

With the development of molecular genetics and NGS, overwhelming evidence has been provided supporting the independent clonal origins of MPLCs, which may contribute to the differential diagnosis of MPLCs from IM. The initial studies sequenced only a few genes such as epidermal growth-factor receptor $(E G F R)$ and kirsten rat sarcoma viral oncogene $(K R A S)$ to improve discrimination between MPLCs and IM. ${ }^{2,47,51}$ However, the clonal origin of multiple tumors is inconclusive when no hotspot driver mutation is identified. Subsequently, NGS screening from 20 to 468 cancer-related genes was applied to identify MPLCs. ${ }^{52-58}$

Seven small studies enrolled a total of 237 patients (range, 11 to 60) and compared the diagnostic efficacy and robustness of the molecular classification with the different histological classifications (Table 2). Overall, NGS provides better discrimination than the clinicopathological classification because it is able to classify more indefinite cases, indicating the importance of NGS. As the numbers of genes sequenced by NGS increase, the ratio of inconclusive cases decreases except in one study. This study sequencing only 20 genes had no equivocal cases, in part because some indefinite cases sharing only one hotspot driver mutation were classified as IM. ${ }^{55}$ In other studies, ${ }^{53,54,56-58}$ large panel NGS may be more functionally valuable in defining clonal relationship of multiple tumors. Sequencing at least 100 cancer-related genes could confirm the clonal 


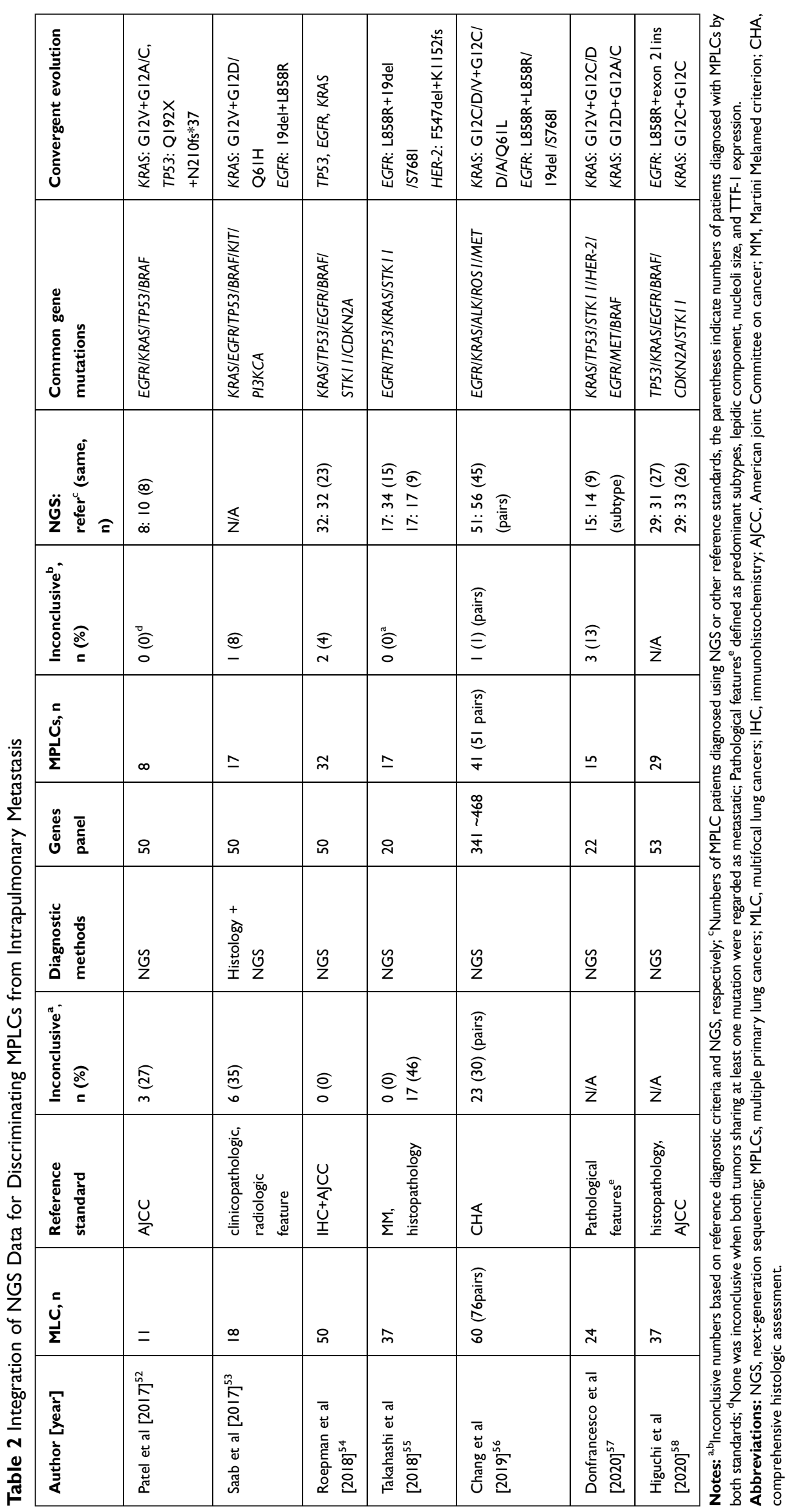


relationship of $95 \%$ of lung adenocarcinomas although the most appropriate detection number of genes remains unknown. Additionally, as shown in Table 2, the molecular classification by NGS conflicts with the histological classification in many cases, and to some extent compensates for the shortcomings of a histological classification. Due to the inconsistencies of multiple reference diagnostic criteria (Table 2) and the absence of a diagnostic gold standard, additional studies are needed to evaluate the utility of NGS and an appropriate number of genes to be sequenced.

In terms of the diagnostic approach using NGS, some studies sequencing about 50 genes proposed that multiple tumors were independent if they harbored different driver mutations, and were metastatic if they shared gene mutations for even just one common driver mutation. ${ }^{52,53,55,57}$ The former could be interpreted by "trunk and branch" theory. ${ }^{59,60}$ Early somatic events triggering oncogenesis are the "trunk" of the tumor, and are present at all tumor sites. Late somatic events as tumors progress are the "branches", and are only present in specific tumor subclones. For the latter, it is inappropriate to diagnose IM based on one common driver mutation. EGFR and KRAS have been reported to be the most frequent driver mutations, ${ }^{54-56,58}$ leading to the fair probability of coincidentally sharing one hotspot driver mutation in independent primary tumors. Under these circumstances, combination with histopathology or more comprehensive genomic profiles is essential. Mansuet-Lupo et al ${ }^{61}$ already proposed an integrated histomolecular algorithm for MPLCs in which the histological algorithm was decisive when multiple tumors shared one frequent driver mutation (EGFR exon 19 deletions or EGFR p.L858R or KRAS p. G12X). Regrettably, there was no significant difference in the 5-year survival rate between MPLCs and IM, indicating that the histomolecular algorithm still needs to be further improved. Broad panel NGS including 341 468 genes has been shown to allow more robust discrimination of the clonality relationship among multifocal lung cancers. ${ }^{56}$ Whole-genome sequencing (WGS) or wholeexome sequencing (WES) provides more comprehensive information for clonality assessment but is unpractical in the clinical setting due to its high cost and requirements for tumor samples. ${ }^{62,63}$

Given that tumor samples are difficult to obtain for gene sequencing for some patients, circulating tumor DNA (ctDNA) released by tumor cells, which is conveniently and noninvasively obtained, may be useful in the detection of gene alterations using NGS. ${ }^{64}$ Two prospective clinical trials (NCT02833467; NCT04326751) have been designed to evaluate the feasibility and application value of identifying genetic mutations in ctDNA for MPLC patients, and the initial results are expected.

Apart from point mutations, chromosomal rearrangements may also be applied to identify MPLCs. Murphy et $\mathrm{al}^{65,66}$ detected somatic breakpoint junctions with matepair sequencing technology to determine the lineage of tumors, and found that independent tumors shared few somatic junctions, while metastatic tumors shared many junctions. No indeterminate case for tumor lineage resulted with mate-pair sequencing technology. Additionally, other methods including microsatellite polymorphism, loss of heterozygosity and comparative genomic hybridization have occasionally been applied to discriminate MPLCs and IM. ${ }^{45,67-69}$ These methods, especially mate-pair sequencing may be promising in patients who are nondefinitive after integrated with clinicopathological and genetic evaluation. However, they are difficult to conduct in a routine clinical setting due to high cost and the inaccessibility of experimental techniques.

DNA methylation, one of the most intensively studied areas of epigenetics, exerts an important role in cellular biology and transcriptional regulation. ${ }^{70}$ Each cell type has a unique DNA methylation profile, which could serve as a tool to trace cell sources of any tumors. ${ }^{71}$ Sano et al $^{72}$ reported a system of analyzing ten gene promoter methylation status and found that primary lung cancer and metastatic tumors shared the same methylation profile while MPLCs differed. It provides a new tool to identify the clonal relationship of multiple lung cancers. Additionally, characteristics of the tumor microenvironment identified by transcriptome sequencing provides new perspectives for identifying MPLCs. ${ }^{73}$ At the protein level, four cancerrelated proteins (p53, p16, p27, and c-erbB2) have been reported to be differentially expressed in MPLCs. ${ }^{74,75}$ If the sum value of the differences in the expression ratios of four proteins between tumors is more than 90, MPLCs will be diagnosed. It may be convenient but there is no reliable control to evaluate the accuracy in the study. Future proteomic studies may excavate more accurate protein biomarkers for distinguishing MPLCs from IM.

Overall, with regard to accuracy and accessibility, large panel NGS may provide an unprecedented opportunity to identify MPLCs accurately in the clinical setting. Moreover, integration of radiological, histopathological, and comprehensive genomic characteristics by a multidisciplinary team may promote more accurate diagnosis for MPLCs. 


\section{Alternative Treatment Options}

\section{Surgery: Unknown Optimal Procedure}

Given that MPLC patients are mostly diagnosed at an early stage, surgery is the preferred treatment for MPLC patients. ${ }^{13}$ However, there is no consensus on the optimum surgical procedure for MPLCs. We systematically reviewed studies about surgical treatments for MPLCs. ${ }^{4,8,9,76-93}$ As shown in Table 3, MPLC patients, especially those presenting with GGOs, could achieve a good 5-year overall survival rate (OS; $\sim 95.8 \%$ ) after surgery and there is a trend toward decreased resection extent and increased survival rate over time. Bilobectomy and pneumonectomy were more common decades ago, while lobectomy and sublobectomy including segmentectomy and wedge resection have become more popular in recent years (Table 3). Currently, controversies remain in choosing either lobectomy or sublobectomy. Shimada et $\mathrm{al}^{84}$ recommended to resect main cancers (larger size or radiologically invasive) with lobectomy and sub-cancers (any other lung cancers) with sublobectomy. Although Zuin et $\mathrm{al}^{4}$ revealed lobectomy was superior to sublobectomy for second primary lung cancer with better 5-year survival $(57.5 \%$ vs $36 \%$; $\mathrm{p}=0.016$ ), others ${ }^{8,94}$ proposed that sublobar resection for the second cancer was safe with acceptable mortality and a 5-year survival rate, especially for patients with limited pulmonary function.

Despite a meta-analysis ${ }^{13}$ and the above studies, some difficulties exist in exploring the optimum type of surgery. As shown in Table 3, the diagnostic criteria employed in the studies are diverse and inaccurate. Next, the starting point for calculating OS is non-uniform, with some studies considering the first surgery and others the second surgery. In the future, standardized and larger studies are warranted to investigate the best operation extent under the premise of accurate diagnosis.

\section{Stereotactic Body Radiation Therapy (SBRT): An Alternative to Surgery}

For MPLC patients who are medically inoperable due to the presence of severe comorbidities and limited cardiopulmonary reserve, there are still some non-surgical treatments including predominantly SBRT $^{95}$ and photodynamic therapy available. ${ }^{96}$ SBRT has been confirmed to be more effective and well tolerated for medically inoperable patients with stage I NSCLC compared with standard radiotherapy. ${ }^{97-99}$ Some studies have also been conducted to explore the value of SBRT in early-stage MPLC patients. ${ }^{16,100-108}$

As shown in Table 4, ten retrospective studies enrolled a total of 510 (range, 10 to 170) MPLC patients treated with SBRT alone or in combination with other therapies including surgery or conventional radiotherapy. Most of patients could not tolerate an operation due to medical comorbidities, while a few refused surgeries. Median OS fluctuated between 15.5 and 46 months. The 2-year progression-free survival (PFS) and 2-year OS rate were 41.$7-95.4 \%, 30-95.4 \%$, respectively. The 2-year local control rate ranged from $75 \%$ to $98.2 \%$ with few grade- 3 or higher toxicities $(0 \sim 11 \%)$. For MPLC patients whose initial cancer was resected, metachronous SBRT for other tumors could achieve a good survival (3-year OS rate: 95.4\%; 3-year PFS rate: 95.4\%). ${ }^{16}$ Moreover, two studies proposed that mMPLCs patients receiving SBRT had a better 2-year PFS and OS rate in comparison with sMPLCs patients. ${ }^{101,103}$ In general, SBRT can achieve a long-term survival and good tumor-control, and is a safe and feasible treatment option for patients with MPLCs, particularly those with limited respiratory function.

\section{Targeted Therapy: Is It Feasible for MPLCs?}

Targeted therapy significantly improved the survival of advanced NSCLC patients with driver gene mutations. ${ }^{109}$ Molecular alterations like EGFR mutation occur frequently in MPLCs, especially those manifesting as GGOs. ${ }^{110-112}$ This allows for consideration of targeted therapy, but no large retrospective studies or clinical trials can guide the application of targeted therapy in MPLC patients. Despite well-established paradigms of targeted therapy for NSCLC patients, the clinical scenarios for MPLC patients are unique in that one lesion harboring a targetable mutation is not representative of all lesions. In fact, the discrepancy rate of driver mutations in MPLCs was reported to be as high as $92 \%$, ${ }^{110,111}$ which has led to different responses to targeted therapy in MPLC patients, and significant challenges to apply targeted drugs to treat MPLCs. ${ }^{113-115}$

With the development of NGS and genome technology, a theory of "convergent evolution" was proposed in MPLC cases. ${ }^{63}$ Heterogeneous driver mutations among tumor foci from the same patient may converge on the same signaling pathway such as EGFR and mitogen-activated protein 
Table 3 Surgical Treatments and Survival Rates of Patients with MPLCs

\begin{tabular}{|c|c|c|c|c|c|c|c|c|c|c|c|}
\hline \multirow[t]{2}{*}{ Authors [year] } & \multirow[t]{2}{*}{ Patients (n) } & \multirow[t]{2}{*}{ Diagnosis } & \multicolumn{5}{|c|}{ Types of surgery } & \multicolumn{4}{|l|}{ Survival } \\
\hline & & & $L+S L$ & $\mathrm{~L}$ & $\mathrm{SL}(\mathrm{s})$ & $\mathrm{BiL}$ & $P$ & Median $(m)$ & 3-year (\%) & 5-year (\%) & $\begin{array}{l}\text { Time to Start } \\
\text { for Survival }\end{array}$ \\
\hline Rea et al $[2001]^{76}$ & $\begin{array}{l}\text { sMPLCs (19) } \\
\text { mMPLCs (61) }\end{array}$ & MM & $\begin{array}{l}11^{\mathrm{a}} \\
0\end{array}$ & $\begin{array}{l}0 \\
49^{b} / 29^{c}\end{array}$ & $\begin{array}{l}3^{\mathrm{a}} \\
10^{\mathrm{b}} / 26^{\mathrm{c}}\end{array}$ & $\begin{array}{l}3^{\mathrm{a}} \\
0\end{array}$ & $\begin{array}{l}2^{\mathrm{a}} \\
2^{\mathrm{b} / 6^{\mathrm{c}}}\end{array}$ & N/A & $N / A$ & $\begin{array}{l}72^{b} \\
51^{c}\end{array}$ & $\begin{array}{l}\text { First surgery } \\
\text { Second surgery }\end{array}$ \\
\hline Aziz et al $[2002]^{77}$ & $\begin{array}{l}\text { sMPLCs (10) } \\
\text { mMPLCs (4I) }\end{array}$ & MM & 9 & I & N/A & 22 & 15 & 40 & N/A & 38 & Second surgery \\
\hline Chang et al $[2007]^{9}$ & sMPLCs (92) & N/A & 14 & 54 & 10 & 8 & 6 & N/A & N/A & 35 & First surgery \\
\hline Trousse et al $[2007]^{78}$ & sMPLCs (125) & MM & 15 & 39 & 21 & 9 & 41 & 35 & $61.6^{\mathrm{d}}$ & 34 & First surgery \\
\hline Leyn et al $[2008]^{79}$ & sMPLCs (36) & Histology & 21 & 0 & 3 & 10 & 2 & 49.4 & $N / A$ & 38 & First surgery \\
\hline Rostad et al $[2008]^{80}$ & sMPLCs (94) & Histology & 11 & 30 & 4 & 8 & 41 & N/A & N/A & 27.6 & N/A \\
\hline Finley et al $[2010]^{81}$ & sMPLCs (175) & Girard & 41 & 59 & 48 & 22 & 5 & 67.4 & 64 & 51 & First surgery \\
\hline Yu et al $[2013]^{82}$ & sMPLCs (97) & MM, Girard & 36 & 39 & 14 & 8 & 0 & 38.3 & 83.1 & 69.6 & First surgery \\
\hline Zuin et al $[2013]^{4}$ & $\begin{array}{l}\text { sMPLCs (23) } \\
\text { mMPLCs (98) }\end{array}$ & MM & 0 & $106^{b} / 44^{c}$ & $10^{b} / 60^{c}$ & 0 & $\begin{array}{l}5^{b} / \\
17^{c}\end{array}$ & N/A & $N / A$ & $\begin{array}{l}76^{b} \\
42^{c}\end{array}$ & $\begin{array}{l}\text { First surgery } \\
\text { Second surgery }\end{array}$ \\
\hline $\begin{array}{l}\text { Ishikawa et al } \\
{[2014]^{83}}\end{array}$ & sMPLCs (93) & $\mathrm{MM}+\mathrm{CHA}$ & 27 & 28 & 27 & 10 & I & N/A & 93.6 & 87 & First surgery \\
\hline $\begin{array}{l}\text { Shimada et al } \\
{[20 \mid 5]^{84}}\end{array}$ & sMPLCs (67) & $\mathrm{MM}, \mathrm{ACCP}$ & 19 & 32 & 11 & 4 & 0 & N/A & $N / A$ & $\begin{array}{l}95.8(\mathrm{GG}) \\
68(\mathrm{GS})\end{array}$ & $N / A$ \\
\hline Dai et al $[2016]^{85}$ & $\begin{array}{l}\text { sMPLCs (27) } \\
\text { mMPLCs (4) }\end{array}$ & MM & 22 & 0 & 0 & 7 & 2 & N/A & 75.8 & 75.8 & $\begin{array}{l}\text { First surgery } \\
\text { Second surgery }\end{array}$ \\
\hline Yang et al $[2016]^{8}$ & $\begin{array}{l}\text { sMPLCs (7I) } \\
\text { mMPLCs (30) }\end{array}$ & MM & 49 & 0 & 13 & 39 & 0 & N/A & 84.5 & 75 & Second surgery \\
\hline Zhang et al $[2016]^{86}$ & sMPLCs (285) & MM & 139 & 44 & 59 & 37 & 6 & $N / A$ & $N / A$ & 77.6 & First surgery \\
\hline Cheng et al $[2017]^{87}$ & sMPLCs (5I) & Girard & 35 & 0 & 9 & 7 & 0 & N/A & 86 & 67 & $N / A$ \\
\hline Peng et al $[2017]^{88}$ & sMPLCs (43) & $\mathrm{MM}, \mathrm{ACCP}$ & 21 & 15 & 6 & 0 & 1 & N/A & 76.7 & $N / A$ & First surgery \\
\hline Xiao et al $[2017]^{89}$ & sMPLCs (52) & MM & 20 & 5 & 18 & 4 & 5 & 52 & N/A & 40.6 & N/A \\
\hline Zhao et al $[2017]^{90}$ & sMPLCs (115) & MM & 0 & $94^{b} / 57^{c}$ & $21^{b} / 58^{c}$ & 0 & 0 & N/A & N/A & $\begin{array}{l}86.5^{\mathrm{b}} \\
69.5^{\mathrm{c}}\end{array}$ & $\begin{array}{l}\text { First surgery } \\
\text { Second surgery }\end{array}$ \\
\hline Chen et al $[2019]^{91}$ & sMPLCs (95) & MM & 58 & 0 & 17 & 20 & 0 & $\mathrm{~N} / \mathrm{A}$ & $N / A$ & 87.4 & First surgery \\
\hline Kang et al $[2019]^{92}$ & $\begin{array}{l}\text { sMPLCs (106) } \\
\text { mMPLCs (36) }\end{array}$ & $N / A$ & 72 & $N / A$ & 18 & 42 & 0 & N/A & $N / A$ & 83 & Second surgery \\
\hline $\begin{array}{l}\text { Fourdrain et al } \\
{[2020]^{93}}\end{array}$ & mMPLCs (55) & $N / A$ & 0 & $9^{b} / 35^{c}$ & $45^{b} / 20^{c}$ & $\begin{array}{l}1 \mathrm{~b} / \\
0^{\mathrm{c}}\end{array}$ & 0 & N/A & 77 & $N / A$ & $N / A$ \\
\hline
\end{tabular}

Notes: Inclusion criteria: studies after 2000 of at least 20 patients with MPLCs reporting survival data; ${ }^{\mathrm{a} O p e r a t i o n a l ~ t y p e s ~ o f ~ s y n c h r o n o u s ~ M P L C s ; ~}{ }^{\mathrm{b}}$ The first operation; 'The second operation; ${ }^{\mathrm{d}} 2$-year survival rate; GG indicates main cancer is ground-glass-opacity dominant and GS indicates main cancer is solid dominant.

Abbreviations: MPLCs, multiple primary lung cancers; L, lobectomy; $(\mathrm{m}) \mathrm{SL}$, sublobectomy or multiple sublobectomies; BiL, bilobectomy; P, pneumonectomy; sMPLCs, synchronous MPLCs; mMPLCs, metachronous MPLCs; MM, Martini and Melamed criterion; N/A, not available; CHA, comprehensive histologic assessment; ACCP, American College of Chest Physicians.

kinase $(M A P K)$ signaling pathways. As shown in Table 2, and therapeutic strategies towards $K R A S$-mutant cancers multiple lung cancers in an individual can harbor mutations in identical or different sites of EGFR or KRAS. incidence of EGFR mutations in lung adenocarcinoma has
KRAS mutations occur in approximately $30 \%$ of cancers,
been reported to range from $47 \sim 64 \%$, ${ }^{117}$ while mutations are currently in preclinical and clinical trial stages. ${ }^{116}$ The 
Table 4 Stereotactic Body Radiation Therapy for Patients with MPLCs

\begin{tabular}{|c|c|c|c|c|c|c|c|c|c|}
\hline Authors [year] & Patients (n) & $\begin{array}{l}\text { SBRT for } \\
>1 \text { lesion, } \\
n\end{array}$ & $\begin{array}{l}\text { SBRT for } \\
\text { I lesion } \\
\text { n }\end{array}$ & $\begin{array}{l}\text { Median } \\
\text { Os, } m\end{array}$ & $\begin{array}{l}\text { 2-year OS, } \\
\%\end{array}$ & $\begin{array}{l}\text { 2-year PFS, } \\
\%\end{array}$ & $\begin{array}{l}\text { 2-year LCR, } \\
\%\end{array}$ & $\begin{array}{l}\text { Grades of } \\
\text { Toxicities, } \\
\%\end{array}$ & $\begin{array}{l}\text { Time to } \\
\text { Start for } \\
\text { Survival }\end{array}$ \\
\hline Sinha et al $[2006]^{100}$ & $\begin{array}{l}\text { sMPLCs (8) } \\
\text { mMPLCs (3) }\end{array}$ & 9 & 1 & 18.5 & 30 & 80 & 80 & $\geq 3(0)$ & N/A \\
\hline Creach et al $[2012]^{101}$ & $\begin{array}{l}\text { sMPLCs (15) } \\
\text { mMPLCs (48) }\end{array}$ & $\begin{array}{l}\mathrm{s}: 11 \\
\mathrm{~m}: 2\end{array}$ & $\begin{array}{l}\mathrm{s}: 4 \\
\mathrm{~m}: 46\end{array}$ & 20 & 58.5 & 41.7 & 90 & $\geq 3(0)$ & First SBRT \\
\hline Matthiesen et al $[2012]^{102}$ & $\begin{array}{l}\text { sMPLCs (8) } \\
\text { mMPLCs (2) }\end{array}$ & 10 & 0 & 15.5 & N/A & $N / A$ & 95.2 & $\geq 3(0)$ & N/A \\
\hline Chang et al $[2013]^{103}$ & $\begin{array}{l}\text { sMPLCs (39) } \\
\text { mMPLCs (62) }\end{array}$ & 29 & 72 & 46 & 73.2 & 67 & 97.4 & $>3(1)$ & $\begin{array}{l}\text { First therapy } \\
\text { Second SBRT }\end{array}$ \\
\hline Griffioen et al $[2013]^{104}$ & sMPLCs (62) & 56 & 6 & 31 & 56 & 62 & 84 & $\geq 3(0)$ & N/A \\
\hline Rahn et al $[2013]^{105}$ & $\begin{array}{l}\text { sMPLCs (6) } \\
\text { mMPLCs (12) }\end{array}$ & 27 & 9 & N/A & 62 & N/A & 81.5 & $\geq 2(17)$ & First SBRT \\
\hline Nishiyama et al $[2015]^{106}$ & mMPLCs (3I) & 0 & 31 & 46 & $62^{*}$ & N/A & N/A & $>3(3)$ & N/A \\
\hline Shintani et al $[2015]^{107}$ & sMPLCs (18) & 15 & 3 & 45.6 & $69.1^{*}$ & $43.2^{*}$ & $77.9^{*}$ & $\geq 3(11)$ & First therapy \\
\hline Nikita et al $[2019]^{16}$ & $\begin{array}{l}\text { sMPLCs (14) } \\
\text { mMPLCs } \\
(156)\end{array}$ & 62 & 108 & 45.6 & $\begin{array}{l}\text { sSBRT: } 46.4^{\mathrm{b}} \\
\text { mSBRT: } 79.7^{\mathrm{b}} \\
\text { Surgery } \\
+ \text { +SBRT: } 95.4^{\mathrm{b}}\end{array}$ & $\begin{array}{l}\text { sSBRT: } 57.5^{\mathrm{b}} \\
\text { mSBRT: } 85.8^{\mathrm{b}} \\
\text { Surgery } \\
+ \text { +SBRT: } 95.4^{\mathrm{b}}\end{array}$ & $\begin{array}{l}\text { sSBRT: } 75.0^{\mathrm{b}} \\
\text { mSBRT: } 96.0^{\mathrm{b}} \\
\text { Surgery } \\
+ \text { +SBRT: } 98.2^{\mathrm{b}}\end{array}$ & $\geq 3(3.5)$ & First therapy \\
\hline Miyazaki et al $[2020]^{108}$ & sMPLCs (26) & 0 & 26 & N/A & 86.3 & N/A & N/A & $\geq 3(3.8)$ & First SBRT \\
\hline
\end{tabular}

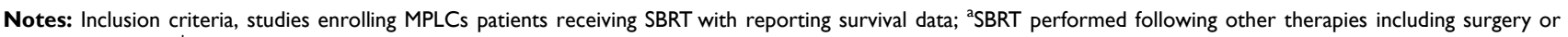

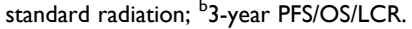

Abbreviations: MPLCs, multiple primary lung cancers; SBRT, stereotactic body radiotherapy; OS, overall survival; PFS, progression-free survival; LCR, local control rate; sMPLCs, synchronous MPLCs; mMPLCs, metachronous MPLCs; sSBRT, synchronous SBRT; mSBRT, metachronous SBRT (>3 months).

at the same or different sites of $E G F R$ gene may occur in up to approximately $45 \%$ of EGFR-positive MPLC patients manifesting as GGOs. ${ }^{110,111}$ Thus, a therapeutic option is available to administer $E G F R$-tyrosine kinase inhibitors for $E G F R$-positive MPLC patients with inoperable lesions. Moreover, Ye et $\mathrm{al}^{113}$ proposed a novel strategy for MPLCs with diverse molecular profiles. The strategy the authors propose achieves a good efficacy, and involves administering gefitinib for the sensitive lesion initially, followed by resection of the gefitinibinsensitive lesion.

In general, despite the possibility of different responses caused by heterogenous molecular events, targeted therapy, particularly EGFR-tyrosine kinase inhibitors, presents a potential alternative therapeutic strategy for MPLC patients, especially for those patients who are medically inoperable. Further investigation is needed to identify common genetic characteristics of all lesions in an individual, which may advance the application of targeted therapy in MPLC patients.

\section{Immune Checkpoint Inhibitors: Should They Be Explored?}

Immune checkpoint inhibitors (ICIs) have been approved as first-line therapy for advanced lung cancer, and have dramatically changed its therapeutic scenario. ${ }^{118}$ Nonetheless, it is unknown if ICIs are effective for MPLC patients, particularly those whose lesions are dispersed and inoperable. There are two active clinical trials in which ICIs are being tested as first-line therapy or neoadjuvant therapy for MPLCs manifesting as GGOs (phase II: NCT04026841; pilot study: NCT04047186). The uncertainties and emerging questions in the burgeoning field of ICIs are worthy of discussion for MPLC patients.

Firstly, programmed-death ligand 1 (PD-L1) is regarded as the most important biomarker for predicting the efficacy of ICIs in lung cancers; ${ }^{119}$ however, little is known about the degree of PD-L1 expression between independent primary tumors in MPLC patients. ${ }^{120-122}$ A retrospective study that enrolled 43 MPLC patients with 112 lesions, reported only 
$13(30.2 \%)$ patients harbored positive PD-L1 expression and 12 of 13 had variable levels of PD-L1 expression. ${ }^{121}$ Another study revealed inconsistent expression of PD-L1 in 11 of 23 patients with MPLCs, and none of the patients was PD-L1positive for all independent lesions. ${ }^{122}$ These studies reveal that the expression level of PD-L1 is not high and is heterogenous as a whole, which presents a significant challenge for treating MPLC patients with ICIs. Secondly, tumor infiltrating lymphocytes have been associated with the response to ICIs. ${ }^{119,123}$ However, characteristics of the tumor microenvironment in patients with MPLCs are unclear. A reported case with synchronous lung adenocarcinoma and squamous cell carcinoma was confirmed to have different proportions of tumor infiltrating lymphocytes in two lesions by performing transcriptomic sequencing. ${ }^{73}$ A clinical trial (NCT04026841) is undergoing to evaluate the characteristics of tumor microenvironment among MPLC patients by performing RNA and $\mathrm{T}$ cell receptor sequencing, but the results will require a substantial length of time to be obtained. Finally, genetic testing is not performed in patients with MPLCs manifesting as GGOs who are enrolled in these clinical trials receiving ICIs treatment. GGOs are often adenocarcinomas that have a relatively higher incidence of driver gene mutations such as EGFR mutation. ${ }^{124}$ There is evidence available indicating that NSCLC patients harboring oncogenic driver alterations, particularly EGFR mutations and $A L K$ fusions, have a lower objective response rate to ICIs. ${ }^{125}$ Similarly, the efficacy of ICIs in MPLC patients may be affected by driver gene mutation status. Therefore, future studies should consider additional factors including the tumor microenvironment and driver gene mutation status before applying ICIs to treat MPLCs.

\section{Conclusion}

Despite great difficulties in discriminating MPLCs from IM, important advancements have been made over the past decades. The current technological advancements allow us to differentially diagnose MPLCs from IM based on a combination of radiological features on CT or PET-CT, histopathological analysis, and molecular characteristics (eg, gene mutations, chromosomal variations, DNA methylation). Broad panel NGS plays a key role in identifying MPLCs, and helps to establish an accurate diagnostic criterion. Importantly, it is recommended that a multidisciplinary team integrate the above resources and be involved in the diagnosis and management of MPLCs.

To date, radical surgery represents the main therapy for MPLCs, but the optimal extent of surgical intervention remains to be standardized. For medically inoperable patients with MPLCs, SBRT is an alternative that presents good efficacy and safety. Additionally, immunotherapy and targeted therapy particularly with EGFR-tyrosine kinase inhibitors are emerging therapeutic options. These novel systematic therapies warrant further investigation of characteristics of both genomic profiles and tumor microenvironment to facilitate their application in MPLCs.

\section{Acknowledgments}

The authors thank Charlesworth Author Services for English language editing.

\section{Disclosure}

The authors declare no conflicts of interest for this work.

\section{References}

1. Siegel RL, Miller KD, Jemal A. Cancer statistics, 2020. CA Cancer J Clin. 2020;70(1):7-30. doi:10.3322/caac.21590

2. Chang Y-L, Wu C-T, Lin S-C, Hsiao C-F, Jou Y-S, Lee Y-C. Clonality and prognostic implications of $\mathrm{p} 53$ and epidermal growth factor receptor somatic aberrations in multiple primary lung cancers. Clin Cancer Res. 2007;13(1):52-58. doi:10.1158/10780432.CCR-06-1743

3. Battafarano RJ, Meyers BF, Guthrie TJ, Cooper JD, Patterson GA. Surgical resection of multifocal non-small cell lung cancer is associated with prolonged survival. Ann Thorac Surg. 2002;74 (4):988-994. doi:10.1016/S0003-4975(02)03878-X

4. Zuin A, Andriolo LG, Marulli G, et al. Is lobectomy really more effective than sublobar resection in the surgical treatment of second primary lung cancer? Eur J Cardiothorac Surg. 2013;44(2):e120e125; discussion e125. doi:10.1093/ejcts/ezt219

5. Stella F, Luciano G, Dell'Amore A, et al. Pulmonary metastases from NSCLC and MPLC (Multiple Primary Lung Cancers): management and outcome in a single centre experience. Heart Lung Circ. 2016;25(2):191-195. doi:10.1016/j.hlc.2015.07.016

6. Mascalchi M, Comin CE, Bertelli E, et al. Screen-detected multiple primary lung cancers in the ITALUNG trial. $J$ Thorac Dis. 2018;10 (2):1058-1066. doi:10.21037/jtd.2018.01.95

7. Boyle JM, Tandberg DJ, Chino JP, D'Amico TA, Ready NE, Kelsey CR. Smoking history predicts for increased risk of second primary lung cancer: a comprehensive analysis. Cancer. 2015;121 (4):598-604. doi:10.1002/cncr.29095

8. Yang H, Sun Y, Yao F, et al. Surgical therapy for bilateral multiple primary lung cancer. Ann Thorac Surg. 2016;101(3):1145-1152. doi:10.1016/j.athoracsur.2015.09.028

9. Chang YL, Wu CT, Lee YC. Surgical treatment of synchronous multiple primary lung cancers: experience of 92 patients. $J$ Thorac Cardiovasc Surg. 2007;134(3):630-637. doi:10.1016/j.jtcvs.20 07.06.001

10. Martini N, Melamed MR. Multiple primary lung cancers. $J$ Thorac Cardiovasc Surg. 1975;70(4):606-612. doi:10.1016/S00225223(19)40289-4

11. Benjamin DK, James ML, Frank CD, David RJ. Special treatment issues in non-small cell lung cancer-diagnosis and management of lung cancer, 3rd ed: American College of Chest physicians evidence-based clinical practice guidelines. Chest. 2013;143(5): e369S-e399S. 
12. Rami-Porta RAH, Travis WD, Rusch VW. AJCC Cancer Staging Manual. 8 ed. France: Springer International Publishing; 2017.

13. Chen T-F, Xie C-Y, Rao B-Y, et al. Surgical treatment to multiple primary lung cancer patients: a systematic review and meta-analysis. BMC Surg. 2019;19(1):185. doi:10.1186/s12893019-0643-0

14. Li R, Li X, Xue R, et al. Early metastasis detected in patients with multifocal pulmonary ground-glass opacities (GGOs). Thorax. 2018;73(3):290-292. doi:10.1136/thoraxjnl-2017-210169

15. Su K, Gao S, Ying J, Zou S, He J. Sequencing a super multiple synchronous lung cancer reveals a novel variant in driver gene ARID1B. J Thorac Cardiovasc Surg. 2018;155(6):e185-e191. doi:10.1016/j.jtcvs.2018.01.010

16. Nikitas J, DeWees T, Rehman S, et al. Stereotactic body radiotherapy for early-stage multiple primary lung cancers. Clin Lung Cancer. 2019;20(2):107-116. doi:10.1016/j.cllc.2018.10.010

17. Detterbeck FC, Jones DR, Kernstine KH, Naunheim KS. Special treatment issues. Chest. 2003;123(1):244S-258S. doi:10.1378/ chest.123.1_suppl.244S

18. Shen KR, Meyers BF, Larner JM, Jones DR. Special treatment issues in lung cancer - ACCP evidence-based clinical practice guidelines (2nd edition). Chest. 2007;132(3):290S-305S. doi:10. 1378/chest.07-1382

19. Groome PA, Bolejack V, Crowley JJ, et al. The IASLC lung cancer staging project: validation of the proposals for revision of the T, N, and $\mathrm{M}$ descriptors and consequent stage groupings in the forthcoming (seventh) edition of the TNM classification of malignant tumours. J Thorac Oncol. 2007;2(8):694-705. doi:10.1097/ JTO.0b013e31812d05d5

20. Detterbeck FC, Franklin WA, Nicholson AG, et al. The IASLC lung cancer staging project: background data and proposed criteria to distinguish separate primary lung cancers from metastatic foci in patients with two lung tumors in the forthcoming eighth edition of the TNM classification for lung cancer. $J$ Thorac Oncol. 2016;11 (5):651-665. doi:10.1016/j.jtho.2016.01.025

21. Detterbeck FC, Boffa DJ, Kim AW, Tanoue LT. The eighth edition lung cancer stage classification. Chest. 2017;151(1):193-203. doi:10.1016/j.chest.2016.10.010

22. Detterbeck FC, Nicholson AG, Franklin WA, et al. The IASLC lung cancer staging project: summary of proposals for revisions of the classification of lung cancers with multiple pulmonary sites of involvement in the forthcoming eighth edition of the TNM classification. $J$ Thorac Oncol. 2016;11(5):639-650.

23. Park E, Ahn S, Kim H, et al. Targeted sequencing analysis of pulmonary adenocarcinoma with multiple synchronous ground-glass/lepidic nodules. $J$ Thorac Oncol. 2018;13 (11):1776-1783. doi:10.1016/j.jtho.2018.07.097

24. Ren YJ, Huang SJ, Dai CY, et al. Germline predisposition and copy number alteration in pre-stage lung adenocarcinomas presenting as ground-glass nodules. Front Oncol. 2019;9:288. doi:10.3389/ fonc. 2019.00288

25. Zhang Y, Li G, Li Y, et al. Imaging features suggestive of multiple primary lung adenocarcinomas. Ann Surg Oncol. 2019;27 (6):2061-2070

26. Matsunaga T, Suzuki K, Takamochi K, Oh S. New simple radiological criteria proposed for multiple primary lung cancers. Jpn J Clin Oncol. 2017;47(11):1073-1077. doi:10.1093/jjco/hyx113

27. Yu F, Tang J, Liu W, et al. Genetic profiling of synchronous multiple primary lung carcinomas presenting as ground-glass opacities. J Clin Oncol. 2019;37(15_suppl):e20034-e20034. doi:10.1200/JCO.2019.37.15_suppl.e20034

28. Travis WD, Brambilla E, Nicholson AG, et al. The 2015 World Health Organization classification of lung tumors: impact of genetic, clinical and radiologic advances since the 2004 classification. J Thorac Oncol. 2015;10(9):1243-1260. doi:10.10 97/JTO.0000000000000630
29. Kadota K, Nitadori J, Sima CS, et al. Tumor spread through air spaces is an important pattern of invasion and impacts the frequency and location of recurrences after limited resection for small stage I lung adenocarcinomas. $J$ Thorac Oncol. 2015;10 (5):806-814. doi:10.1097/JTO.0000000000000486

30. Hara K, Mizuguchi S, Okada S, et al. Intensity of SLX predicts distance of tumor spread through alveolar spaces in stage I lung adenocarcinoma. Thorac Cancer. 2019;10(4):832-838. doi:10. 1111/1759-7714.13008

31. Kadota K, Kushida Y, Kagawa S, et al. Limited resection Is associated with a higher risk of locoregional recurrence than lobectomy in stage I lung adenocarcinoma with tumor spread through air spaces. Am J Surg Pathol. 2019;43(8):1033-1041. doi:10.1097/ PAS.0000000000001285

32. Eguchi T, Kameda K, Lu S, et al. Lobectomy is associated with better outcomes than sublobar resection in Spread through Air Spaces (STAS)-positive T1 lung adenocarcinoma: a propensity score-matched analysis. J Thorac Oncol. 2019;14(1):87-98. doi:10.1016/j.jtho.2018.09.005

33. Shiono S, Endo M, Suzuki K, Yarimizu K, Hayasaka K, Yanagawa N. Spread through air spaces is a prognostic factor in sublobar resection of non-small cell lung cancer. Ann Thorac Surg. 2018;106(2):354-360. doi:10.1016/j.athoracsur.20 18.02.076

34. Dijkman BG, Schuurbiers OCJ, Vriens D, et al. The role of 18F-FDG PET in the differentiation between lung metastases and synchronous second primary lung tumours. Eur J Nucl Med Mol Imaging. 2010;37(11):2037-2047. doi:10.1007/s00259010-1505-2

35. Liu Y, Tang Y, Xue Z, et al. SUVmax ratio on PET/CT may differentiate between lung metastases and synchronous multiple primary lung cancer. Acad Radiol. 2020;27(5):618-623. doi:10.1016/j.acra.2019.07.001

36. Suh YJ, Lee HJ, Sung P, et al. A novel algorithm to differentiate between multiple primary lung cancers and intrapulmonary metastasis in multiple lung cancers with multiple pulmonary sites of involvement. J Thorac Oncol. 2020;15(2):203-215. doi:10.1016/j. jtho.2019.09.221

37. Hosny A, Parmar C, Quackenbush J, Schwartz LH, Aerts H. Artificial intelligence in radiology. Nat Rev Cancer. 2018;18 (8):500-510. doi:10.1038/s41568-018-0016-5

38. Topol EJ. High-performance medicine: the convergence of human and artificial intelligence. Nat Med. 2019;25(1):44-56. doi:10.1038/ s41591-018-0300-7

39. Bera K, Schalper KA, Rimm DL, Velcheti V, Madabhushi A. Artificial intelligence in digital pathology - new tools for diagnosis and precision oncology. Nat Rev Clin Oncol. 2019;16(11):703-715. doi:10.1038/s41571-019-0252-y

40. Nishio M, Sugiyama O, Yakami M, et al. Computer-aided diagnosis of lung nodule classification between benign nodule, primary lung cancer, and metastatic lung cancer at different image size using deep convolutional neural network with transfer learning. PLoS One. 2018;13(7): 0200721.

41. Nasrullah N, Sang J, Alam MS, Mateen M, Cai B, Hu H. Automated lung nodule detection and classification using deep learning combined with multiple strategies. Sensors (Basel). 2019;19(17):3722.

42. Travis WD, Elizabeth B, Konrad M-H, Harris CC. World Health Organization Classification of Tumours. Pathology and Genetics of Tumours of the Lung, Pleura, Thymus and Heart. Lyon, France: IARC Press; 2004.

43. Girard N, Deshpande C, Lau C, et al. Comprehensive histologic assessment helps to differentiate multiple lung primary nonsmall cell carcinomas from metastases. Am J Surg Pathol. 2009;33 (12):1752-1764. doi:10.1097/PAS.0b013e3181b8cf03 
44. Travis WD, Brambilla E, Burke A, Marx A, Nicholson AG. WHO Classification of Tumours of the Lung, Pleura, Thymus and Heart. 4th ed., Vol. 7. Lyon, France: International Agency for Research on Cancer; 2015.

45. Sun W, Feng L, Yang X, et al. Clonality assessment of multifocal lung adenocarcinoma by pathology evaluation and molecular analysis. Hum Pathol. 2018;81:261-271. doi:10.1016/j.humpath. 2018.01.030

46. Sun W, Liu Y, Liu XY, Lin DM, Lv N. Significance of nonmucinous lepidic component with mild nuclear atypia in the discrimination of multiple primary lung cancers from intrapulmonary metastases. Int J Clin Exp Pathol. 2014;7(11):7583-7596.

47. Matsuzoe D, Hideshima T, Ohshima K, Kawahara K, Shirakusa T, Kimura A. Discrimination of double primary lung cancer from intrapulmonary metastasis by $\mathrm{p} 53$ gene mutation. $\mathrm{Br} \mathrm{J}$ Cancer. 1999;79(9-10):1549-1552. doi:10.1038/sj.bjc.6690247

48. Iwata T, Sugio K, Uramoto H, et al. Detection of EGFR and K-ras mutations for diagnosis of multiple lung adenocarcinomas. Front Biosci (Landmark Ed). 2011;16:2961-2969. doi:10.2741/3891

49. Ikeda K, Nomori H, Ohba Y, et al. Epidermal growth factor receptor mutations in multicentric lung adenocarcinomas and atypical adenomatous hyperplasias. J Thorac Oncol. 2008;3(5):467-471. doi:10.1097/JTO.0b013e31816b4b14

50. Chung J-H, Choe G, Jheon S, et al. Epidermal growth factor receptor mutation and pathologic-radiologic correlation between multiple lung nodules with ground-glass opacity differentiates multicentric origin from intrapulmonary spread. $J$ Thorac Oncol. 2009;4(12):1490-1495. doi:10.1097/JTO.0b013e3181bc9731

51. Takamochi K, Oh S, Matsuoka J, Suzuki K. Clonality status of multifocal lung adenocarcinomas based on the mutation patterns of EGFR and K-ras. Lung Cancer. 2012;75(3):313-320. doi:10.1016/ j.lungcan.2011.08.007

52. Patel SB, Kadi W, Walts AE, et al. Next-generation sequencing: a novel approach to distinguish multifocal primary lung adenocarcinomas from intrapulmonary metastases. J Mol Diagn. 2017;19 (6):870-880. doi:10.1016/j.jmoldx.2017.07.006

53. Saab J, Zia H, Mathew S, Kluk M, Narula N, Fernandes H. Utility of genomic analysis in differentiating synchronous and metachronous lung adenocarcinomas from primary adenocarcinomas with intrapulmonary metastasis. Transl Oncol. 2017;10(3):442-449. doi:10.1016/j.tranon.2017.02.009

54. Roepman P, Ten Heuvel A, Scheidel KC, et al. Added value of 50 -gene panel sequencing to distinguish multiple primary lung cancers from pulmonary metastases: a systematic investigation. $J \mathrm{Mol}$ Diagn. 2018;20(4):436-445. doi:10.1016/j.jmoldx.2018.02.007

55. Takahashi Y, Shien K, Tomida S, et al. Comparative mutational evaluation of multiple lung cancers by multiplex oncogene mutation analysis. Cancer Sci. 2018;109(11):3634-3642. doi:10.1111/cas.13797

56. Chang JC, Alex D, Bott M, et al. Comprehensive next-generation sequencing unambiguously distinguishes separate primary lung carcinomas from intrapulmonary metastases: comparison with standard histopathologic approach. Clin Cancer Res. 2019;25 (23):7113-7125. doi:10.1158/1078-0432.CCR-19-1700

57. Donfrancesco E, Yvorel V, Casteillo F, et al. Histopathological and molecular study for synchronous lung adenocarcinoma staging. Virchows Arch. 2020;476(6):835-842. doi:10.1007/s00428-019-02736-0

58. Higuchi R, Nakagomi T, Goto $T$, et al. Identification of clonality through genomic profile analysis in multiple lung cancers. J Clin Med. 2020;9(2):573. doi:10.3390/jcm9020573

59. Yap TA, Gerlinger M, Futreal PA, Pusztai L, Swanton C. Intratumor heterogeneity: seeing the wood for the trees. Sci Transl Med. 2012;4 (127):127ps110. doi:10.1126/scitranslmed.3003854

60. Swanton C. Intratumor heterogeneity: evolution through space and time. Cancer Res. 2012;72(19):4875-4882. doi:10.1158/00085472.CAN-12-2217
61. Mansuet-Lupo A, Barritault M, Alifano M, et al. Proposal for a combined histomolecular algorithm to distinguish multiple primary adenocarcinomas from intrapulmonary metastasis in patients with multiple lung tumors. J Thorac Oncol. 2019;14(5):844-856. doi:10.1016/j.jtho.2019.01.017

62. Liu Y, Zhang JJ, Li L, et al. Genomic heterogeneity of multiple synchronous lung cancer. Nat Commun. 2016;7:13200. doi:10.10 38/ncomms 13200

63. Ma P, Fu Y, Cai MC, et al. Simultaneous evolutionary expansion and constraint of genomic heterogeneity in multifocal lung cancer. Nat Commun. 2017;8(1):823. doi:10.1038/s41467-01700963-0

64. Abbosh C, Birkbak NJ, Swanton C. Early stage NSCLC - challenges to implementing ctDNA-based screening and MRD detection. Nat Rev Clin Oncol. 2018;15(9):577-586.

65. Murphy SJ, Harris FR, Kosari F, et al. Using genomics to differentiate multiple primaries from metastatic lung cancer. $J$ Thorac Oncol. 2019;14(7):1567-1582. doi:10.1016/j.jtho.2019.05.008

66. Murphy SJ, Aubry MC, Harris FR, et al. Identification of independent primary tumors and intrapulmonary metastases using DNA rearrangements in non-small-cell lung cancer. $J$ Clin Oncol. 2014;32(36):4050-4058. doi:10.1200/JCO.2014.56.7644

67. Shen C, Wang X, Tian L, et al. "Different trend" in multiple primary lung cancer and intrapulmonary metastasis. Eur $J$ Med Res. 2015;20(1):17. doi:10.1186/s40001-015-0109-5

68. Tian L, Wang X, Zeng RJ, et al. Microsatellite alteration in plasma DNA discriminates multiple primary lung cancer from metastatic lung cancer. Transl Cancer Res. 2017;6(4):720-731. doi:10.21037/ tcr.2017.07.07

69. Wang X, Wang M, MacLennan GT, et al. Evidence for common clonal origin of multifocal lung cancers. J Natl Cancer Inst. 2009;101(8):560-570. doi:10.1093/jnci/djp054

70. Skvortsova K, Stirzaker C, Taberlay P. The DNA methylation landscape in cancer. Essays Biochem. 2019;63(6):797-811.

71. Dor Y, Cedar H. Principles of DNA methylation and their implications for biology and medicine. Lancet. 2018;392(10149):777-786. doi:10.1016/S0140-6736(18)31268-6

72. Sano A, Kage H, Sugimoto K, et al. A second-generation profiling system for quantitative methylation analysis of multiple gene promoters: application to lung cancer. Oncogene. 2007;26 (45):6518-6525. doi:10.1038/sj.onc. 1210483

73. Wu L, Kang P, Tao S, et al. Genomic profiles and transcriptomic microenvironments in 2 patients with synchronous lung adenocarcinoma and lung squamous cell carcinoma: a case report. $B M C$ Med Genomics. 2020;13(1):15.

74. Ono K, Sugio K, Uramoto H, et al. Discrimination of multiple primary lung cancers from intrapulmonary metastasis based on the expression of four cancer-related proteins. Cancer. 2009;115 (15):3489-3500. doi:10.1002/cncr.24382

75. Chen DL, Mei LY, Zhou YB, et al. A novel differential diagnostic model for multiple primary lung cancer: differentially-expressed gene analysis of multiple primary lung cancer and intrapulmonary metastasis. Oncol Lett. 2015;9(3):1081-1088. doi:10.3892/ol.2015.2880

76. Rea F, Zuin A, Callegaro D, Bortolotti L, Guanella G, Sartori F. Surgical results for multiple primary lung cancers. Eur J Cardiothorac Surg. 2001;20(3):489-495. doi:10.1016/S10107940(01)00858-2

77. Aziz TM, Saad RA, Glasser J, Jilaihawi AN, Prakash D. The management of second primary lung cancers. A single centre experience in 15 years. Eur J Cardiothorac Surg. 2002;21 (3):527-533. doi:10.1016/S1010-7940(02)00024-6

78. Trousse D, Barlesi F, Loundou A, et al. Synchronous multiple primary lung cancer: an increasing clinical occurrence requiring multidisciplinary management. $J$ Thorac Cardiovasc Surg. 2007;133(5):1193-1200. doi:10.1016/j.jtcvs.2007.01.012 
79. De Leyn P, Moons J, Vansteenkiste J, et al. Survival after resection of synchronous bilateral lung cancer. Eur J Cardiothorac Surg. 2008;34(6):1215-1222.

80. Rostad H, Strand TE, Naalsund A, Norstein J. Resected synchronous primary malignant lung tumors: a population-based study. Ann Thorac Surg. 2008;85(1):204-209. doi:10.1016/j.athoracsur.2007.07.091

81. Finley DJ, Yoshizawa A, Travis W, et al. Predictors of outcomes after surgical treatment of synchronous primary lung cancers. $J$ Thorac Oncol. 2010;5(2):197-205. doi:10.1097/JTO.0b0 $13 \mathrm{e} 3181 \mathrm{c} 814 \mathrm{c} 5$

82. Yu Y-C, Hsu P-K, Yeh Y-C, et al. Surgical results of synchronous multiple primary lung cancers: similar to the stage-matched solitary primary lung cancers? Ann Thorac Surg. 2013;96(6):1966-1974. doi:10.1016/j.athoracsur.2013.04.142

83. Ishikawa $\mathrm{Y}$, Nakayama H, Ito H, et al. Surgical treatment for synchronous primary lung adenocarcinomas. Ann Thorac Surg. 2014;98(6):1983-1988. doi:10.1016/j.athoracsur.2014.07.006

84. Shimada Y, Saji H, Otani K, et al. Survival of a surgical series of lung cancer patients with synchronous multiple ground-glass opacities, and the management of their residual lesions. Lung Cancer. 2015;88(2):174-180. doi:10.1016/j.lungcan.2015.02.016

85. Dai L, Yang HL, Yan WP, et al. The equivalent efficacy of multiple operations for multiple primary lung cancer and a single operation for single primary lung cancer. $J$ Thorac Dis. 2016;8(5):855-861. doi:10.21037/jtd.2016.03.42

86. Zhang Z, Gao S, Mao Y, et al. Surgical outcomes of synchronous multiple primary non-small cell lung cancers. Sci Rep. 2016;6:23252. doi:10.1038/srep23252

87. Cheng H, Lei BF, Peng PJ, Lin YJ, Wang XJ. Histologic lung cancer subtype differentiates synchronous multiple primary lung adenocarcinomas from intrapulmonary metastases. J Surg Res. 2017;211:215-222. doi:10.1016/j.jss.2016.11.050

88. Peng Y, Ren W, Wang H, Li M, Feng Z, Peng Z. Surgical treatment is an effective approach for patients with synchronous multiple primary lung cancers. J Cancer Res Ther. 2017;13(4):702-706. doi:10.4103/jcrt.JCRT_140_17

89. Xiao F, Liu D, Guo Y, et al. Survival rate and prognostic factors of surgically resected clinically synchronous multiple primary non-small cell lung cancer and further differentiation from intrapulmonary metastasis. J Thorac Dis. 2017;9(4):990-1001. doi:10.21037/jtd.2017.03.59

90. Zhao H, Yang H, Han K, et al. Clinical outcomes of patients with metachronous second primary lung adenocarcinomas. Onco Targets Ther. 2017;10:295-302. doi:10.2147/OTT.S122908

91. Chen H, Fu Q, Sun K. Efficacy and prognosis analysis of surgical treatment for bilateral synchronous multiple primary non-small cell lung cancer. J BUON. 2019;24(6):2245-2252.

92. Kang X, Zhang $\mathrm{C}$, Zhou $\mathrm{H}$, et al. Multiple pulmonary resections for synchronous and metachronous lung cancer at two Chinese centers. Ann Thorac Surg. 2020;109(3):856-863. doi:10.1016/j.athoracsur.2019.09. 088

93. Fourdrain A, Bagan P, Georges O, et al. Outcomes after contralateral anatomic surgical resection in multiple lung cancer. Thorac Cardiovasc Surg. 2020.

94. Lee D-S, LaChapelle C, Taioli E, et al. Second primary lung cancers demonstrate similar survival with wedge resection and lobectomy. Ann Thorac Surg. 2019;108(6):1724-1728. doi:10.10 16/j.athoracsur.2019.06.023

95. Owen D, Olivier KR, Mayo CS, et al. Outcomes of stereotactic body radiotherapy (SBRT) treatment of multiple synchronous and recurrent lung nodules. Radiat Oncol. 2015;10:43. doi:10.1186/ s13014-015-0340-9

96. Usuda J, Ichinose S, Ishizumi T, et al. Management of multiple primary lung cancer in patients with centrally located early cancer lesions. $J$ Thorac Oncol. 2010;5(1):62-68. doi:10.1097/ JTO.0b013e3181c42287
97. Grills IS, Mangona VS, Welsh R, et al. Outcomes after stereotactic lung radiotherapy or wedge resection for stage I non-small-cell lung cancer. J Clin Oncol. 2010;28(6):928-935. doi:10.1200/ JCO.2009.25.0928

98. Videtic GMM, Donington J, Giuliani M, et al. Stereotactic body radiation therapy for early-stage non-small cell lung cancer: executive summary of an ASTRO evidence-based guideline. Pract Radiat Oncol. 2017;7(5):295-301. doi:10.1016/j.prro.2017.04.014

99. Howington JA, Blum MG, Chang AC, Balekian AA, Murthy SC. Treatment of stage I and II non-small cell lung cancer: diagnosis and management of lung cancer, 3rd ed: American College of Chest Physicians evidence-based clinical practice guidelines. Chest 2013;143(5Suppl):e278S-e313S. doi:10.1378/chest.12-2359

100. Sinha B, McGarry RC. Stereotactic body radiotherapy for bilateral primary lung cancers: the Indiana University experience. Int J Radiat Oncol Biol Phys. 2006;66(4):1120-1124. doi:10.10 16/j.ijrobp.2006.06.042

101. Creach KM, Bradley JD, Mahasittiwat P, Robinson CG. Stereotactic body radiation therapy in the treatment of multiple primary lung cancers. Radiother Oncol. 2012;104(1):19-22. doi:10.1016/j.radonc.2011.12.005

102. Matthiesen C, Thompson JS, De La Fuente Herman T, Ahmad S, Herman T. Use of stereotactic body radiation therapy for medically inoperable multiple primary lung cancer. $J$ Med Imaging Radiat Oncol. 2012;56(5):561-566. doi:10.1111/j.1754-9485.2012.02393.X

103. Chang JY, Liu YH, Zhu Z, et al. Stereotactic ablative radiotherapy: a potentially curable approach to early stage multiple primary lung cancer. Cancer. 2013;119(18):3402-3410. doi:10.1002/cncr.28217

104. Griffioen GH, Lagerwaard FJ, Haasbeek CJ, Smit EF, Slotman BJ, Senan S. Treatment of multiple primary lung cancers using stereotactic radiotherapy, either with or without surgery. Radiother Oncol. 2013;107(3):403-408. doi:10.1016/j.radonc.2013.04.026

105. Rahn DA 3rd, Thakur S, Makani S, Sandhu A. Stereotactic body radiation therapy (SBRT) for multiple primary lung cancers (MPLC): a review and case series. J Radiosurg SBRT. 2013;2 (2):135-140.

106. Nishiyama K, Kodama K, Teshima T, Tada H. Stereotactic body radiotherapy for second pulmonary nodules after operation for an initial lung cancer. Jpn J Clin Oncol. 2015;45(10):947-952. doi:10.1093/jjco/hyv113

107. Shintani T, Masago K, Takayama K, et al. Stereotactic body radiotherapy for synchronous primary lung cancer: clinical outcome of 18 cases. Clin Lung Cancer. 2015;16(5):e91-e96. doi:10.1016/j. cllc.2014.12.011

108. Miyazaki T, Yamazaki T, Sato S, et al. Surgery or stereotactic body radiotherapy for metachronous primary lung cancer? A propensity score matching analysis. Gen Thorac Cardiovasc Surg. 2020. doi:10.1007/s11748-020-01394-3

109. Arbour KC, Riely GJ. Systemic therapy for locally advanced and metastatic non-small cell lung cancer: a review. JAMA. 2019;322 (8):764-774. doi:10.1001/jama.2019.11058

110. Wu CY, Zhao C, Yang Y, et al. High discrepancy of driver mutations in patients with NSCLC and synchronous multiple lung ground-glass nodules. J Thorac Oncol. 2015;10(5):778-783. doi:10.1097/JTO.0000000000000487

111. Liu M, He WX, Song N, Yang Y, Zhang P, Jiang GN. Discrepancy of epidermal growth factor receptor mutation in lung adenocarcinoma presenting as multiple ground-glass opacities. Eur J Cardiothorac Surg. 2016;50(5):909-913. doi:10.1093/ejcts/ezw113

112. Yang Y, Yin W, He W, et al. Phenotype-genotype correlation in multiple primary lung cancer patients in China. Sci Rep. 2016;6 (1):36177. doi:10.1038/srep36177

113. Ye C, Wang J, Li W, Chai Y. Novel strategy for synchronous multiple primary lung cancer displaying unique molecular profiles. Ann Thorac Surg. 2016;101(2):e45-e47. doi:10.1016/j. athoracsur.2015.06.042 
114. Ryoo BY, Na II, Yang SH, Koh JS, Kim CH, Lee JC. Synchronous multiple primary lung cancers with different response to gefitinib. Lung Cancer. 2006;53(2):245-248. doi:10.1016/j.lungcan.2006. 05.010

115. Bao Y, Wu J, Zhang J, Yu Y. Diagnosis and treatment of synchronous multiple primary lung cancer - a case report. Onco Targets Ther. 2019;12:4281-4285. doi:10.2147/OTT.S183319

116. Liu P, Wang Y, Li X. Targeting the untargetable KRAS in cancer therapy. Acta Pharm Sin B. 2019;9(5):871-879. doi:10.1016/j. apsb.2019.03.002

117. Sun F, Xi J, Zhan C, et al. Ground glass opacities: imaging, pathology, and gene mutations. J Thorac Cardiovasc Surg. 2018;156(2):808-813. doi:10.1016/j.jtcvs.2018.02.110

118. Proto C, Ferrara R, Signorelli D, et al. Choosing wisely first line immunotherapy in non-small cell lung cancer (NSCLC): what to add and what to leave out. Cancer Treat Rev. 2019;75:39-51. doi:10.1016/j.ctrv.2019.03.004

119. Yi M, Jiao D, Xu H, et al. Biomarkers for predicting efficacy of PD-1/PD-L1 inhibitors. Mol Cancer. 2018;17(1):129. doi:10.1186/ s12943-018-0864-3

120. Tokuyasu H, Horie M, Ishikawa S, Sakai H, Miura H, Yamasaki A. Multiple lung cancers including squamous cell carcinoma with strong PD-L1 expression and adenocarcinoma with EGFR exon 19 deletion: a case report. Respir Med Case Rep. 2020;29:100976.
121. Haratake N, Toyokawa G, Takada K, et al. Programmed death-ligand 1 expression and EGFR mutations in multifocal lung cancer. Ann Thorac Surg. 2018;105(2):448-454. doi:10.1016/j. athoracsur.2017.09.025

122. Mansfield AS, Murphy SJ, Peikert T, et al. Heterogeneity of programmed cell death ligand 1 expression in multifocal lung cancer. Clin Cancer Res. 2016;22(9):2177-2182. doi:10.1158/1078-0432. CCR-15-2246

123. Galon J, Bruni D. Approaches to treat immune hot, altered and cold tumours with combination immunotherapies. Nat Rev Drug Discov. 2019;18(3):197-218.

124. Kobayashi Y, Ambrogio C, Mitsudomi T. Ground-glass nodules of the lung in never-smokers and smokers: clinical and genetic insights. Transl Lung Cancer Res. 2018;7(4):487-497. doi:10.21037/tlcr.2018.07.04

125. Mazieres J, Drilon A, Lusque A, et al. Immune checkpoint inhibitors for patients with advanced lung cancer and oncogenic driver alterations: results from the IMMUNOTARGET registry. Ann Oncol. 2019;30(8):1321-1328. doi:10.1093/annonc/mdz 167

\section{Publish your work in this journal}

Cancer Management and Research is an international, peer-reviewed open access journal focusing on cancer research and the optimal use of preventative and integrated treatment interventions to achieve improved outcomes, enhanced survival and quality of life for the cancer patient.
The manuscript management system is completely online and includes a very quick and fair peer-review system, which is all easy to use. Visit http://www.dovepress.com/testimonials.php to read real quotes from published authors. 